\title{
CONVERSÃO DOS USOS DA TERRA (2000-2005 E 2005- 2010) NAS ÁREAS INCORPORADAS COM CANA-DE- AÇÚCAR NA MICRORREGIÃO DE FRUTAL -MG
}

\author{
Laís Naiara Gonçalves dos Reis ${ }^{1}$
}

\author{
Josimar dos Reis Souza ${ }^{2}$
}

\begin{abstract}
RESUMO
Pode-se observar que as áreas ocupadas com a cultura da cana-de-açúcar têm expandido suas fronteiras no Brasil, substituindo as áreas que antes eram ocupadas por pastagens e agriculturas. Alteração explicada pelo aumento da demanda do etanol, agrocombustível. Essa pesquisa tem como finalidade mapear a expansão da cana-de-açúcar na microrregião de Frutal, e como esse processo tem ocasionado à substituição das áreas de cultura agrícola, pastagens e cobertura vegetal natural pela monocultura referida. Foram utilizadas as imagens (Landsat e Rapideye), o georreferenciamento foi feito no SPRING 5.2 (Software de SIG livre, disponível no site do INPE). O Processamento Digital das Imagens e a classificação em tela do computador foram feitas no software SPRING 5.2. Os municípios de Frutal, Fronteira, Planura e Pirajuba são os que possuem as áreas mais antigas da cultura de canade-açúcar referente ao período mapeado, desde 2000. A maioria das novas áreas incorporadas pela cana-de-açúcar nessa região se deu sobre as áreas de pastagens, tanto para o primeiro período, quanto para o segundo.
\end{abstract}

PALAVRAS-CHAVE: mapeamento, expansão canavieira, Frutal.

\section{CONVERSION OF LAND USES (2000-2005 and 2005-2010) INCORPORATED IN AREAS WITH CANE SUGAR IN THE REGION OF FRUTAL-MG}

\begin{abstract}
It can be observed that the areas occupied by the culture of sugar cane have expanded their frontiers in Brazil, replacing the areas that were once used for pasture and agriculture. Amendment explained by increased demand for ethanol biofuel. This research aims to map the spread of cane sugar in the region of Frutal, and how this process has led to the replacement of areas of crop, pasture and natural vegetation cover by monoculture said. Were used Images (Landsat and RapidEye), the georeferencing was done in SPRING 5.2 (free GIS software, available on the website INPE). The Digital Processing of Images and rankings on the computer screen were made in SPRING 5.2 software too. The municipalities of Frutal, Fronteira, Planura and Pirajuba are those with the oldest areas of the culture of sugar cane according to the mapping Concerning the period since 2000. Most new areas incorporated by the sugar cane in this region occurred on the pasture areas, both for the first time, as for the second.
\end{abstract}

\footnotetext{
${ }^{1}$ Doutoranda em Geografia-UFU, Msc. em Geografia -UFU, Técnica de laboratório de Cartografia do Instituto de Geografia-UFU. E-mail: laisngr@ufu.br

${ }^{2}$ Geógrafo, Mestrando em Geografia-UFU, Bacharel em Geografia-UFU. E-mail.
} 


\section{CONVERSIÓN DE USOS DE LA TIERRA (2000-2005 y 2005- 2010) INCORPORADO EN ZONAS CON CAÑA DE AZÚCAR EN LA REGION DE FRUTAL-MG}

\section{RESUMEN}

Pode-se observar que as áreas ocupadas com a cultura da cana-de-açúcar têm expandido suas fronteiras no Brasil, substituindo as áreas que antes eram ocupadas por pastagens e agriculturas. Alteração explicada pelo aumento da demanda do etanol, agrocombustível. Essa pesquisa tem como finalidade mapear a expansão da cana-de-açúcar na microrregião de Frutal, e como esse processo tem ocasionado à substituição das áreas de cultura agrícola, pastagens e cobertura vegetal natural pela monocultura referida. Foram utilizadas as imagens (Landsat e Rapideye), o georreferenciamento foi feito no SPRING 5.2 (Software de SIG livre, disponível no site do INPE). O Processamento Digital das Imagens e a classificação em tela do computador foram feitas no software SPRING 5.2. Os municípios de Frutal, Fronteira, Planura e Pirajuba são os que possuem as áreas mais antigas da cultura de canade-açúcar referente ao período mapeado, desde 2000. A maioria das novas áreas incorporadas pela cana-de-açúcar nessa região se deu sobre as áreas de pastagens, tanto para o primeiro período, quanto para o segundo.

PALABRAS-CLAVE mapeo, expansión de la caña, Frutal.

\section{INTRODUÇÃO}

O uso dessas novas formas de obtenção de energia surgiu devido às especulações financeiras sobre o novo paradigma da sustentabilidade ambiental. Atualmente, o Brasil é líder nas tecnologias de produção do etanol extraído da canade-açúcar, sendo responsável por $45 \%$ da produção mundial, feita em mais de 400 usinas e destilarias (BARROS, E.V, 2007; GONÇALVES, 2009).

O segmento sucroalcooleiro tem participado ativamente da atividade agrícola brasileira. Na safra 2007/2008, o Brasil produziu, aproximadamente, 22,5 bilhões de litros de álcool, dos quais grande parte foi destinada ao mercado interno, que vem ganhando destaque no segmento agroindustrial brasileiro, devido à retomada do aumento do consumo doméstico em decorrência do preço competitivo desse combustível em relação à gasolina (EMBRAPA, 2010).

Esse cenário contribuiu para a expansão da cana-de-açúcar desde 2000 na microrregião de Frutal-MG. A área de estudo é composta pelos seguintes municípios: Campina Verde, Carneirinho, Comendador Gomes, Fronteira, Frutal, Itapagipe, Iturama, Limeira do Oeste, Planura, Pirajuba, São Francisco de Sales e União de 
Minas (Figura 1). A abundância de água na microrregião é devido à bacia do Rio Grande, por isso a região se constitui como propícia para expansão da cana-deaçúcar, uma vez que o processo produtivo dos derivados da cana demanda por bastante água.

Figura 1: Localização: Microrregião de Frutal-MG

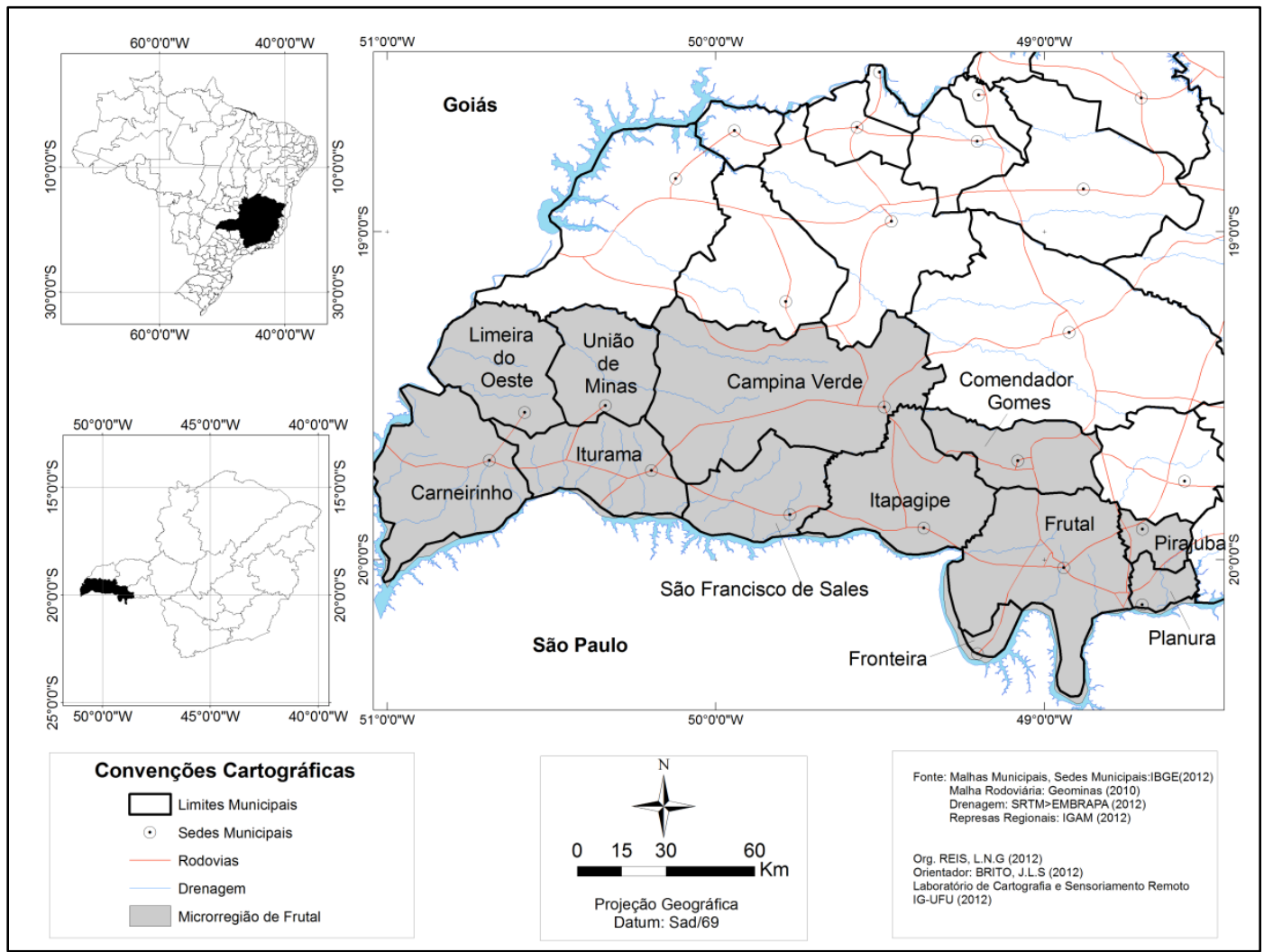

Fonte: REIS, 2012.

O setor sucroalcooleiro contribui para ambos os setores do PIB (Agropecuária, Indústria e Serviços) uma vez que, a cadeia produtiva envolve tanto no consumo de insumos para produção (produtos químicos e maquinários), transporte (prestação de serviços) e na quantidade em toneladas produzidas por hectares de cana-de-açúcar. Mas, como os valores adicionados ao PIB de serviços, muitas vezes ultrapassam as fronteiras dos municípios, fica mais fácil observar o valor produzido por hectare e atividade das usinas, no que refere a transformação da cana-de-açúcar para outro produto (açúcar, álcool ou energia). 
Nessa microrregião, a atividade relacionada ao setor agropecuário adicionou cerca de 733.063.000reais em 2009. Os municípios que possuíam maior PIB adicionado pela atividade agropecuária eram: Frutal, Itapagipe e Iturama (tabela 1).

Tabela 1. PIB relativo à agropecuária, Indústria e Serviços: microrregião de Frutal (2009)

\begin{tabular}{l|rr|r|r} 
Município & \multicolumn{1}{|l|}{$\begin{array}{l}\text { Área } \\
\left(\mathbf{k m}^{2}\right)\end{array}$} & \multicolumn{1}{l|}{$\begin{array}{l}\text { PIB } \\
\text { Agropecuária } \\
\text { (R\$) }\end{array}$} & $\begin{array}{l}\text { PIB } \\
\text { Indústria } \\
\text { (R\$) }\end{array}$ & $\begin{array}{l}\text { PIB do } \\
\text { Serviços (R\$) }\end{array}$ \\
\hline Campina Verde & 3.650 & 72.892 .000 & 21.683 .000 & 110.250 .000 \\
Carneirinho & 2063 & 69.511 .000 & 28.667 .000 & 63.004 .000 \\
Comendador Gomes & 1.041 & 71.885 .000 & 2.569 .000 & 25.568 .000 \\
Fronteira & 200 & 26.197 .000 & 590.309 .000 & 83.577 .000 \\
Frutal & 2.426 & 240.639 .000 & 118.906 .000 & 378.211 .000 \\
Itapagipe & 1.802 & 88.927 .000 & 53.172 .000 & 80.380 .000 \\
Iturama & 1.404 & 81.696 .000 & 156.598 .000 & 277.332 .000 \\
Limeira do Oeste & 1.319 & 59.436 .000 & 20.478 .000 & 44.003 .000 \\
Planura & 317 & 41.545 .000 & 172.088 .000 & 117.307 .000 \\
Pirajuba & 338 & 53.227 .000 & 48.857 .000 & 52.862 .000 \\
\hline Total & $\mathbf{1 1 . 0 0 0}$ & $\mathbf{7 3 3 . 0 6 3 . 0 0 0}$ & $\mathbf{1 . 1 9 1 . 6 4 4 . 0 0 0}$ & $\mathbf{1 . 1 2 2 . 2 4 4 . 0 0 0}$ \\
& \multicolumn{2}{|c|}{ Fonte: IBGE, 2009. Org. REIS, L.N.G (2012) }
\end{tabular}

O sensoriamento remoto tem se demonstrado eficiente para o levantamento dessa cultura no espaço, possibilitando o mapeamento das áreas plantadas que auxiliam na compreensão do processo de expansão dessa cultura. Assim, essa pesquisa tem como finalidade mapear a expansão da cana-de-açúcar da microrregião de Frutal, e compreender como esse processo tem ocasionado à substituição das áreas de culturas agrícolas, pastagens e cobertura vegetal natural pela monocultura referida.

Os objetivos específicos da pesquisa foram: a) mapear as áreas ocupadas com cana-de-açúcar em 2010 na microrregião de Frutal e b) mapear o uso da Terra e Cobertura vegetal em 2000 e 2005 das áreas ocupadas com cana-de-açúcar em 2010 na área de estudo.

Em relação aos procedimentos metodológicos, inicialmente, as imagens Landsat (2000 2 2005) e Rapideye (2010) foram registradas no SPRING 5.2 (Software de SIG livre, disponível no site do INPE), tomando como referência as cartas 
topográficas do IBGE e DSG na escala de 1:100.000. Após o registro, foi aplicado um contraste no SPRING 5.2, usando o método de equalização do histograma para as imagens Landsat e Rapideye, depois foi feito um mosaico das mesmas. Foi feito uma fotointerpretação para os seguintes alvos cana-de-açúcar, pastagem, silvicultura, agricultura e vegetação natural, como indica o quadro 1.

Quadro1. Chave de Interpretação utilizada para o mapeamento do uso em 2000 e 2005 das áreas ocupadas com cana-de-açúcar na região do Triângulo Mineiro (2010), composição colorida (3b4r5g)

\begin{tabular}{|c|c|c|c|}
\hline 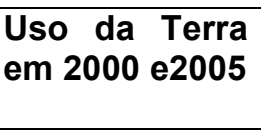 & Descrição do Uso & $\begin{array}{l}\text { Padrões } \\
\text { característicos de } \\
\text { interpretação }\end{array}$ & Exemplo \\
\hline $\begin{array}{l}1 \text { - cana-de- } \\
\text { açúcar }\end{array}$ & $\begin{array}{l}\text { Áreas que eram cana-de- } \\
\text { açúcar; }\end{array}$ & $\begin{array}{l}\text { Textura Lisa, Padrão } \\
\text { Geométrico, Tonalidade } \\
\text { Azul, Roxa e Vermelha }\end{array}$ & \\
\hline 2 - Agricultura & $\begin{array}{l}\text { Áreas utilizadas com culturas } \\
\text { anuais ou perenes; }\end{array}$ & $\begin{array}{l}\text { Textura Lisa, Padrão } \\
\text { Geométrico, Tonalidade } \\
\text { Verde, Laranja e } \\
\text { Vermelha. }\end{array}$ & \\
\hline 3 - Pastagem & $\begin{array}{lcr}\text { Áreas } & \text { utilizadas } & \text { com } \\
\text { pastagens } & \text { plantadas } & \text { ou } \\
\text { naturais; } & & \\
\end{array}$ & $\begin{array}{l}\text { Textura média, Padrão } \\
\text { Geométrico, Tonalidade } \\
\text { Amarelo, Verde e } \\
\text { Vermelha. }\end{array}$ & \\
\hline 4 - Silvicultura & $\begin{array}{l}\text { Áreas de reflorestamento de } \\
\text { Pinus ou Eucalipto; }\end{array}$ & $\begin{array}{l}\text { Textura rugosa, Padrão } \\
\text { Geométrico, Tonalidade } \\
\text { Vermelho escuro. }\end{array}$ & \\
\hline $\begin{array}{l}\text { 5-Cobertura } \\
\text { Vegetal Natural }\end{array}$ & $\begin{array}{l}\text { Nesta categoria estão } \\
\text { incluídas as áreas de cerrado } \\
\text { ou mata; }\end{array}$ & $\begin{array}{l}\text { Textura rugosa, Padrão } \\
\text { irregular, } \quad \text { Tonalidade } \\
\text { Vermelho médio e escuro. }\end{array}$ & \\
\hline
\end{tabular}

Org. REIS, L.N. G (2014)

\section{DESENVOLVIMENTO}

Em todos os municípios há presença de cana-de-açúcar desde o ano 2000. Por essa microrregião fazer fronteira com o Estado de São Paulo, a torna como área de expansão da cana-de-açúcar, uma vez que esse Estado é onde possui maior área em 
extensão da cultura, e uma infraestrutura já estabelecida, antes mesmo do ano 2000 (tabela 2).

Tabela 2. Área total de cultura temporária (ha) e porcentagem de cana-de-açúcar.

\begin{tabular}{|c|c|c|c|c|c|c|}
\hline Municípios & 2000 & $\%$ & 2005 & $\%$ & 2010 & $\%$ \\
\hline Campina Verde & 8.240 & 0 & 8.500 & 0 & 11.955 & 80 \\
\hline Carneirinho & 4.124 & 11 & 2.677 & 7 & 7.680 & 91 \\
\hline Comendador Gomes & 2.529 & 1 & 4.504 & 15 & 3.366 & 30 \\
\hline Fronteira & 6.157 & 67 & 5.040 & 89 & 6.720 & 79 \\
\hline Municípios & 2000 & $\%$ & 2005 & $\%$ & 2010 & $\%$ \\
\hline Frutal & 30.246 & 2 & 47.161 & 17 & 45.439 & 68 \\
\hline Itapagipe & 7.942 & 10 & 6.810 & 0 & 14.020 & 64 \\
\hline Iturama & 23.077 & 85 & 25.073 & 85 & 31.700 & 97 \\
\hline Limeira do Oeste & 6.801 & 37 & 7.079 & 100 & 18.551 & 97 \\
\hline Pirajuba & 20.083 & 31 & 19.400 & 23 & 22.100 & 63 \\
\hline Planura & 26.159 & 8 & 28.550 & 19 & 16.340 & 46 \\
\hline São Francisco de Sales & 1.124 & 11 & 7.190 & 7 & 12.722 & 94 \\
\hline União de Minas & 4.832 & 66 & 6.871 & 78 & 16.277 & 98 \\
\hline Total & 141.314 & & 168.855 & & 206.870 & \\
\hline
\end{tabular}

Como resultado da pesquisa, no período de 2000-2005 houve um aumento da cana-de-açúcar na microrregião de 19 \% de 195.027 ha, e 44\% em relação ao total da área que existia em 2005. O mapeamento multitemporal da cana-de-açúcar indica o município de Frutal como sendo o que possui a maior quantidade em extensão da cultura desde 2000, sendo que houve um incremento de $40 \%$ no período de 2005 para 2010 em relação ao total da área existente em 2005. Seguido pelo município de Iturama e Pirajuba (gráfico 1).

Gráfico1. Expansão da cana-de-açúcar (2000, 2005 e 2010): microrregião de Frutal-MG. 


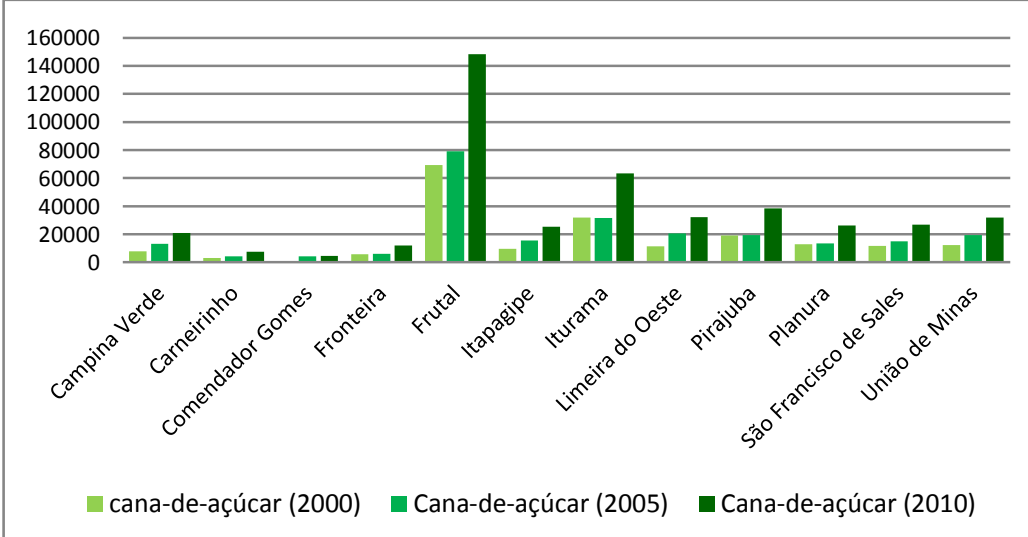

Org. REIS, L. N.G (2012)

A infraestrutura voltada para o setor sucroalcooleiro possibilita compreender o uso da terra ocupado pela cana-de-açúcar bem como sua expansão (BELIK, 2007; CARVALHO, 2012). Essa microrregião possui 12 usinas. Sendo que, os municípios que possuem usinas instaladas são: Campina Verde, Carneirinho, Comendador Gomes, Fronteira, Itapagipe, Iturama, Pirajuba e União de Minas tem uma unidade cada e Limeira do Oeste e Frutal com duas unidades.

Segundo o site da Usina Coruripe Filial de Iturama (figura 2), essa foi a primeira unidade industrial do Grupo Tércio Wanderley em Minas Gerais. Seu funcionamento se deu em 1994, após a incorporação da Destilaria Alexandre Balbo, que operava naquela localidade desde 1985. Em seguida, foi construída a fábrica de açúcar, anexa à destilaria,o que explica a área de aproximadamente 32.000 ha de cana-de-açúcar em 2000, ou seja, uma área antiga da monocultura na região de estudo. No período de (2000-2010) a área de cana-de-açúcar praticamente dobrou nesse município.

Figura 2. Usina Coruripe Filial de Iturama.

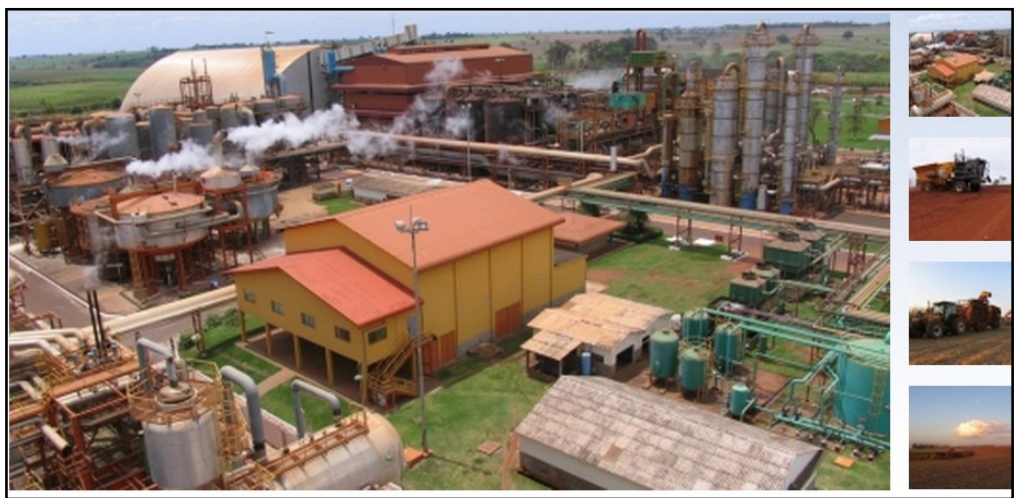

Fonte: (Usina Coruripe, 2012) 
O Grupo Tércio Wanderley também é dono da Filial Limeira do Oeste (figura 3) que foi inaugurada em 2005. Esta unidade se beneficia da proximidade entre as usinas, pondo em prática um modelo de gestão único, o que possibilita economia e eficiência em seus resultados. A Filial Limeira do Oeste desenvolveu um projeto de irrigação, por meio da força da gravidade, para distribuir água e vinhaça aos canaviais (Usina Coruripe, 2012). No período de 2005 até 2010, houve uma expansão de $35 \%$ em relação á área plantada de cana-de-açúcar no município que era de 31.500 ha em 2005.

Figura 3. Filial da Usina Coruripe: Limeira do Oeste.

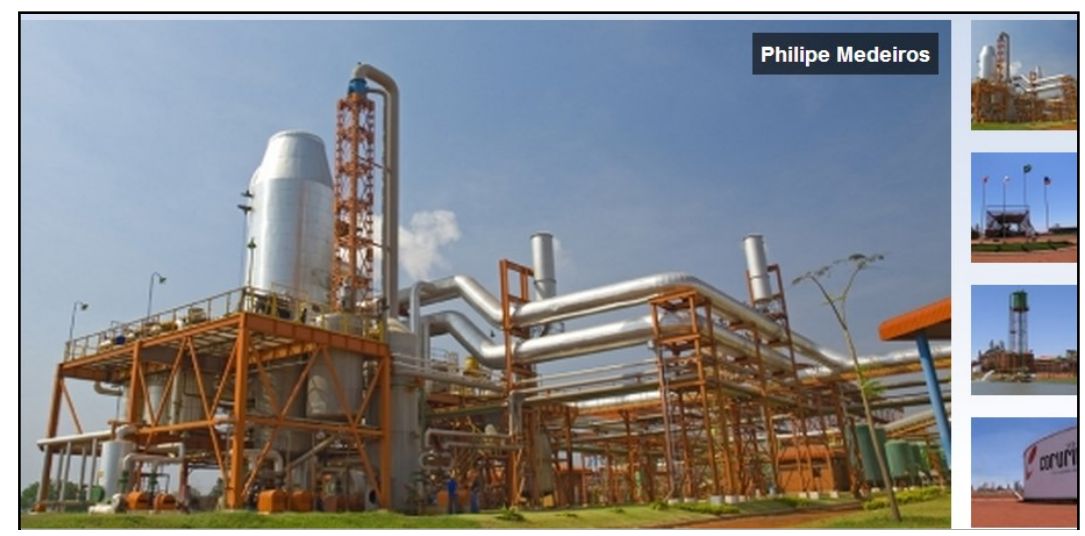

Fonte: Usina Coruripe, 2012.

Em 2001, para aproveitar a quantidade de bagaço que as usinas do Grupo Tércio Wanderley produziam, foi criada uma unidade de cogeração de energia elétrica na Filial de Iturama (figura 4), dando origem à Coruripe Energética que comercializa energia, gerando 3 bilhões de watts por ano. Atualmente, o Grupo produz $124 \mathrm{MW} / \mathrm{h}$ de energia, sendo que $60 \mathrm{MW} / \mathrm{h}$ é destinado para consumo interno e o restante é comercializado. Essa unida de tem potencial de expandir para mais $190 \mathrm{MW} / \mathrm{h}$ (Usina Coruripe, 2012). 
Figura 4. Coruripe Energética: Iturama.

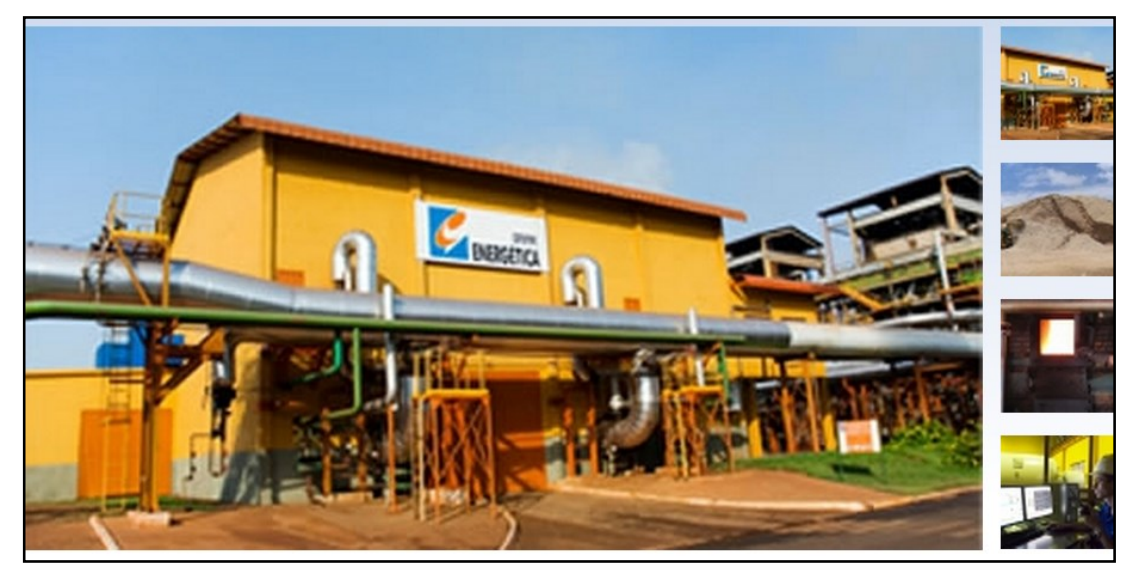

Fonte: Usina Coruripe, 2012.

A usina presente em Carneirinho (figura 5) é outra empresa do Grupo Tércio Wanderley. Essa foi inaugurada em 2008, é voltada para a produção de açúcar. "Em crescente desenvolvimento, na safra 2010/2011 esmagou 1,5 milhão de tonelada de cana, produzindo 3,48 milhões de sacos de $50 \mathrm{Kg}$ de açúcar e 19,51 milhões de litros de álcool." (Usina Coruripe, 2012) .

Figura 5. Usina Coruripe Agroindustrial: Carneirinho-MG

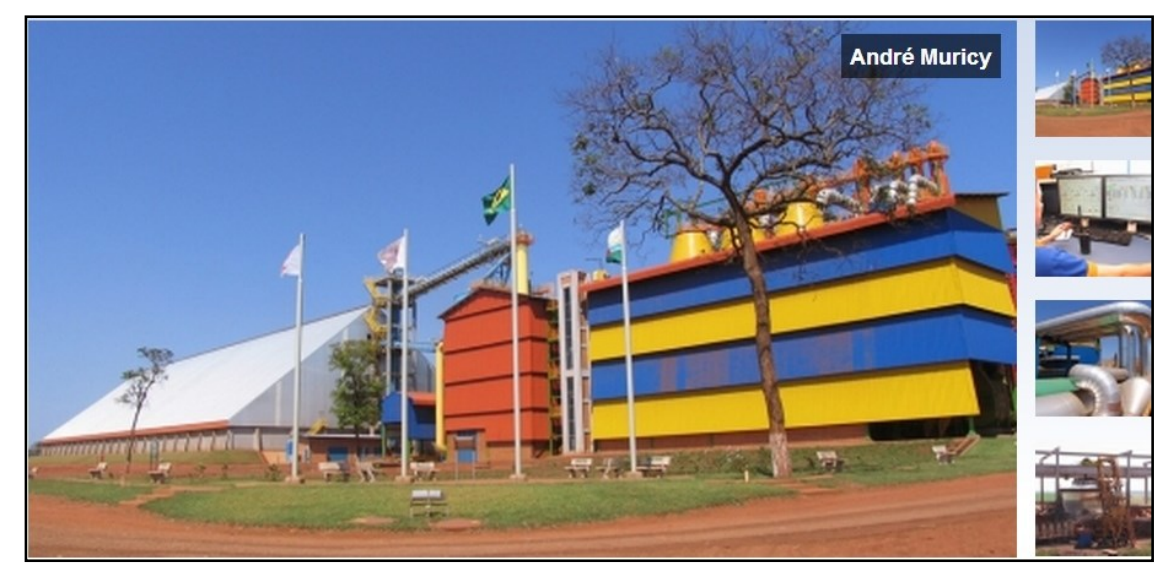

Fonte: (Usina Coruripe, 2012)

Outro empreendimento do Grupo Tércio Wanderley na microrregião é a Usina União de Minas Agroindustrial Açúcar e Álcool Ltda. localizada no município de União de Minas, essa unidade começou a funcionar em 2008, voltada para destilação de 
álcool, fabricação de açúcar e cogeração de energia termoelétrica. O Jornal Cana entrevistou o Vitor Montenegro Wanderley Júnior que apresentou expectativas para a instalação da usina desde 2004:

De acordo com Vitor Montenegro Wanderley Junior, a unidade de União de Minas deverá ser uma destilaria autônoma dedicada a exportação de álcool principalmente para a China e Japão. A moagem está prevista para 2007/08, com capacidade total para 1,5 milhão de toneladas de cana, produzir aproximadamente 140 milhões de litros ou mais e empregar de 2,5 mil a 3 mil pessoas. (Jornal Cana, 2004, sp.)

Carneirinho possuía pouca área de cana-de-açúcar entre o período de 2000 até 2005, após 2005 a área aumentou devido especulações para o funcionamento da Usina que seria instalada no município, houve assim, uma expansão de $60 \%$ da área em relação a quantidade que existia em 2000, totalizando 7.400 ha em 2010.

A usina Itapagipe Açúcar e Álcool Ltda. foi criada em 2006, pertencia ao Grupo Moema. Tanto essa Usina quanto a Usina Frutal foram incorporadas pelo Grupo BUNGE em 2010 (BUNGE, 2012). A outra usina do município de Frutal (Usina Cerradão Ltda.) foi criada também em 2006, essa pertence ao grupo Queiroz de Queiroz. Portanto, essa região que integra os dois municípios tem uma expansão acentuada da cana-de-açúcar no período de 2005 á 2010. O município de Frutal incrementa cerca de $45 \%$ da área de cana-de-açúcar em relação à 2005 , que era de 75.000 ha, aproximadamente. E o município de Itapagipe aumenta $37 \%$ da área plantada com cana-de-açúcar em relação a 2005, que era de 15.600 há, aproximadamente.

O mapa da figura 6 mostra o uso da terra e cobertura vegetal natural (2000, 2005 e 2010): para a microrregião de Frutal-MG. Os municípios de Frutal, Fronteira, Planura e Pirajuba são os que possuem as áreas mais antigas da cultura de cana-deaçúcar referente ao período mapeado, desde 2000. A maioria das novas áreas incorporadas pela cana-de-açúcar nessa região se deu sobre as áreas de pastagens, tanto para o primeiro período, quanto para o segundo. 
Figura 6. Mapeamento do uso da terra e cobertura vegetal natural (2000 e 2005) para as áreas de cana-de-açúcar em 2010: microrregião de Frutal-MG.

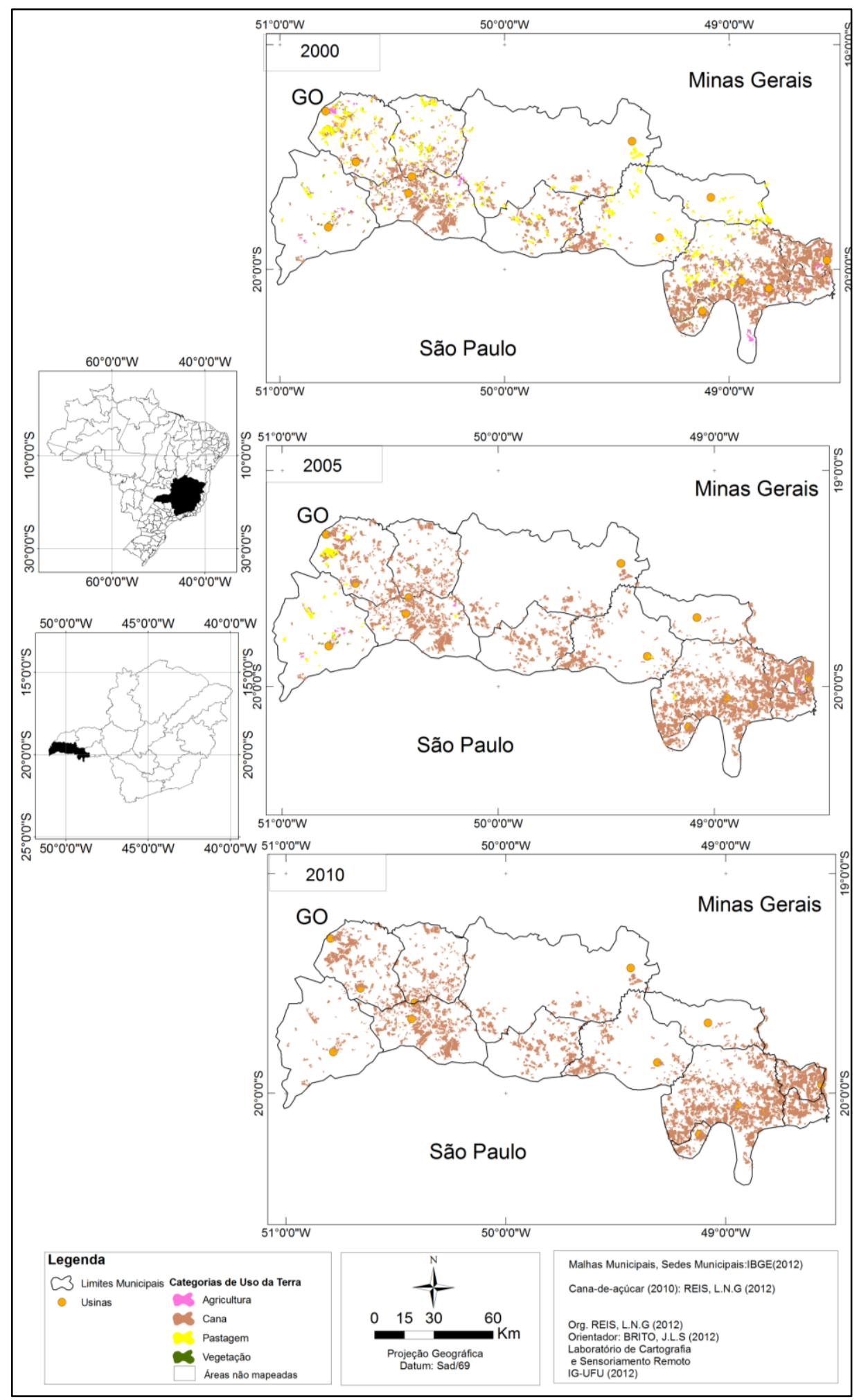

Org. REIS, L.N.G (2012) 
No primeiro período (2000-2005), a expansão da cana-de-açúcar em primeiro lugar se deu sobre as áreas de pastagens (gráfico 2), sobretudo nos municípios de Limeira do Oeste (21\%), Frutal (15\%), Itapagipe (14\%) e Campina Verde $(11 \%)$ do total de 44.618 ha. Em segundo lugar, as novas áreas de cana ocuparam áreas que antes eram de vegetação natural em: Frutal $(27 \%)$, Iturama (18\%) e Carneirinho (13\%) de 8.376 ha. (Tabela 3)

Gráfico 1. Conversão dos usos da terra (2000 -2005) das áreas de expansão da cana-de-açúcar em 2010: microrregião de Frutal-MG

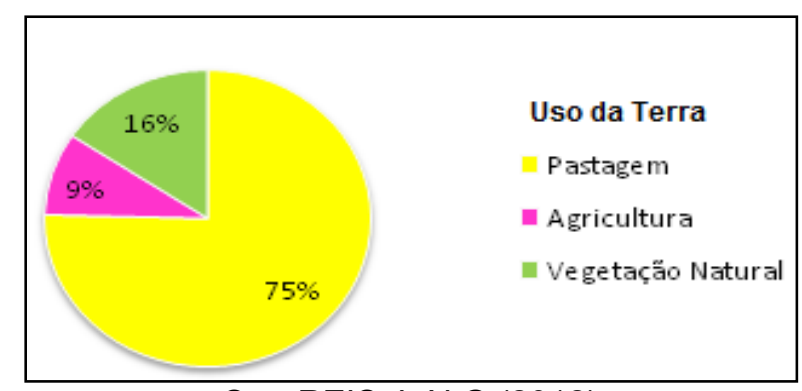

Org. REIS, L.N.G (2012)

Tabela 3. Categorias do uso da Terra em 2000 das áreas ocupadas com cana-de-açúcar em 2010: microrregião de Frutal-MG

\begin{tabular}{|c|c|c|c|c|c|c|c|c|}
\hline \multirow[t]{2}{*}{ Municípios } & \multicolumn{2}{|c|}{ Pastagem } & \multicolumn{2}{|c|}{ Agricultura } & \multicolumn{2}{|c|}{$\begin{array}{l}\text { Vegetação } \\
\text { Natural }\end{array}$} & \multicolumn{2}{|c|}{ Cana-de-açúcar } \\
\hline & (ha) & $(\%)$ & (ha) & $(\%)$ & (ha) & $(\%)$ & (ha) & $(\%)$ \\
\hline Campina Verde & 5.041 & 11 & 234 & 4 & 249 & 3 & 7682 & 4 \\
\hline Carneirinho & 2.073 & 5 & 835 & 15 & 1.066 & 13 & 3187 & 2 \\
\hline $\begin{array}{l}\text { Comendador } \\
\text { Gomes }\end{array}$ & 3.665 & 8 & 36 & 1 & 255 & 3 & 313 & 0 \\
\hline Fronteira & 68 & 0 & 0 & 0 & 250 & 3 & 5.819 & 3 \\
\hline Frutal & 6.752 & 15 & 1.115 & 20 & 2.239 & 27 & 69.232 & 35 \\
\hline Itapagipe & 6.121 & 14 & 15 & 0 & 188 & 2 & 9.550 & 5 \\
\hline Iturama & 1.892 & 4 & 462 & 8 & 1.504 & 18 & 31.957 & 16 \\
\hline Limeira do Oeste & 9.549 & 21 & 2.128 & 38 & 1.004 & 12 & 11.361 & 6 \\
\hline Pirajuba & 0 & 0 & 485 & 9 & 360 & 4 & 19.003 & 10 \\
\hline Planura & 0 & 0 & 258 & 5 & 224 & 3 & 12.886 & 7 \\
\hline $\begin{array}{l}\text { São Francisco de } \\
\text { Sales }\end{array}$ & 2.768 & 6 & 0 & 0 & 500 & 6 & 11.752 & 6 \\
\hline União de Minas & 6.690 & 15 & 14 & 0 & 569 & 7 & 12.285 & 6 \\
\hline Total & 44.618 & 100 & 5.581 & 100 & 8.376 & 100 & 195.027 & 100 \\
\hline
\end{tabular}

Org. REIS, L.N.G (2012) 
No segundo período analisado (2005-2010) houve um aumento nas categorias de conversão do uso da terra: sobre as áreas de agricultura o valor passou de $9 \%$ para $13 \%$; sobre as áreas de pastagens, de $75 \%$ para $82 \%$. Das áreas novas de cana-de-açúcar sobre a área de vegetação natural houve uma redução de $16 \%$ para $5 \%$ dessa categoria.

$\mathrm{Na}$ tabela 4 observa-se que o município de Limeira do Oeste concentra a maior área convertida de pastagem para cana-de-açúcar, no segundo período (2005-2010) com $55 \%$ de 5.989 ha, seguido pelo município de Carneirinho com $36 \%$.

Tabela 1. Categorias do uso da Terra em 2005 das áreas ocupadas com cana-de-açúcar em 2010: microrregião de Frutal-MG

\begin{tabular}{|c|c|c|c|c|c|c|c|c|}
\hline \multirow[t]{2}{*}{ Municípios } & \multicolumn{2}{|c|}{ Pastagem } & \multicolumn{2}{|c|}{ Agricultura } & \multicolumn{2}{|c|}{$\begin{array}{l}\text { Vegetação } \\
\text { Natural }\end{array}$} & \multicolumn{2}{|c|}{ Cana-de-açúcar } \\
\hline & (ha) & (\%) & (ha) & $(\%)$ & (ha) & (\%) & (ha) & (\%) \\
\hline Campina Verde & 0 & 0 & 0 & 0 & 0 & 0 & 13.205 & 5 \\
\hline Carneirinho & 2.139 & 36 & 517 & 54 & 247 & 62 & 4.256 & 2 \\
\hline $\begin{array}{l}\text { Comendador } \\
\text { Gomes }\end{array}$ & 0 & 0 & 0 & 0 & 0 & 0 & 4.239 & 2 \\
\hline Fronteira & 0 & 0 & 0 & 0 & 0 & 0 & 6.137 & 3 \\
\hline Frutal & 284 & 5 & 0 & 0 & 0 & 0 & 79.054 & 33 \\
\hline Itapagipe & 0 & 0 & 0 & 0 & 0 & 0 & 15.673 & 6 \\
\hline Iturama & 279 & 5 & 162 & 17 & 15 & 4 & 31.501 & 13 \\
\hline Limeira do Oeste & 3.287 & 55 & 0 & 0 & 62 & 16 & 20.693 & 9 \\
\hline Pirajuba & 0 & 0 & 278 & 29 & 20 & 5 & 19.550 & 8 \\
\hline Planura & 0 & 0 & 0 & 0 & 0 & 0 & 13.368 & 6 \\
\hline $\begin{array}{l}\text { São Francisco de } \\
\text { Sales }\end{array}$ & 0 & 0 & 0 & 0 & 0 & 0 & 15.020 & 6 \\
\hline União de Minas & 0 & 0 & 0 & 0 & 52 & 13 & 19.506 & 8 \\
\hline Total & 5.989 & 100 & 957 & 100 & 396 & 100 & 242.202 & 100 \\
\hline
\end{tabular}

Org. REIS, L.N.G (2012)

No que diz respeito á conversão dos demais usos da agricultura para a cana estimou-se uma área de 957 ha na microrregião, sendo $54 \%$ do total em Carneirinho e $29 \%$ em Pirajuba. O maior desmatamento da cobertura vegetal natural para o plantio da cana ocorreu no município de Carneirinho, com 62\% de 396 hectares. 


\section{CONCLUSÃO}

O mapeamento da cana-de-açúcar na microrregião de Frutal contribuiu para um diagnóstico, um primeiro olhar da paisagem buscando conhecer a expansão e a incorporação de novas áreas na região. Essa escala contribui para estudos regionais que buscam caracterizar a dinâmica agroindustrial recente.

As imagens Rapideye foram importantes para mapear com maior precisão a área ocupada com cana-de-açúcar em junho de 2010, em conjunto com as imagens do sensor TM/Landsat foi possível obter resultados satisfatórios para estimar a conversão dos demais usos da terra para cana-de-açúcar e embasar as discussões desse fenômeno para a região.

\section{REFERÊNCIAS}

BELIK, W. Agroindústria e política agroindustrial no Brasil. In: Pedro Ramos [et al].

Dimensões do agronegócio brasileiro: políticas, instituições e perspectivas. Brasília: MDA, 2007, p.141-170.

CARVALHO, E. R. Pontal do Triângulo mineiro: as atuais transformações territoriais do complexo sucroalcooleiro. Disponível em:<

http://www.geografiaememoria.ig.ufu.br/downloads/Joao_Cleps_Junior_PONTAL_DO_TRIANGULO_MI NEIRO_AS_ATUAIS_TRANSFORMACOES.pdf> Acessado em dezembro de 2012.

CLEPS Jr. Concentração de poder no agronegócio e (des)territorialização: os Impactos da expansão recente do capital sucroalcooleiro no Triângulo Mineiro. In: Caminhos de Geografia Uberlândia, v. 10, n. 31 Set/2009 p. 249 - 264. Disponível

em:<http://www.sumarios.org/sites/default/files/pdfs/51097_5994.PDF>Acessado em junho de 2012.

CONAB - Companhia Nacional de Abastecimento. Acompanhamento de safra brasileira: Cana-deaçúcar - safra 2009: segundo levantamento, setembro/2009. Brasília: Conab, 2009.pp. 1-14 Disponível: http://www.conab.gov.br/conabweb/download/safra/2_levantamento2009_set2009.pdf. Acessado em: setembro de 2009.

EMBRAPA. Agência de Informação: cana-de-açúcar. Disponível em: < http://www.agencia.cnptia.embrapa.br/gestor/cana-deacucar/arvore/CONTAG01_110_22122006154841.html> Acessado em maio de 2010.

GONÇALVES, D. B. Considerações sobre a expansão recente da lavoura canavieira no Brasil. In: Informações Econômicas, SP, v.39, n.10, out. 2009. 
JORNAL CANA. Grupo Tércio Wanderley Lança Pedra Fundamental De Destilaria Em União De Minas. Disponível do sítio: <http://www.jornalcana.com.br/noticia/Jornal-Cana/3115+Grupo-TercioWanderley-lanca-pedra-fundamental-de-destilaria-em-Uniao-de-Minas> 